\title{
Laboreal
}

Volume 9 NN$^{\circ} 2$ | 2013

Varia

\section{¿Hasta qué punto y cómo puede conceptualizarse el trabajo informal?}

Até que ponto e como podemos conceptualizar o trabalho informal?

Jusqu'où et comment peut-on conceptualiser le travail informel ?

Limits of conceptualizing informal work?

\section{Tine Manvoutouka}

\section{OpenEdition}

Journals

Edición electrónica

URL: http://journals.openedition.org/laboreal/5674

DOI: $10.4000 /$ laboreal. 5674

ISSN: 1646-5237

Editor

Universidade do Porto

Referencia electrónica

Tine Manvoutouka, « ¿Hasta qué punto y cómo puede conceptualizarse el trabajo informal ? », Laboreal [En línea], Volume 9 N² | 2013, Publicado el 01 diciembre 2013, consultado el 05 octubre 2019. URL : http://journals.openedition.org/laboreal/5674; DOI : 10.4000/laboreal.5674

Este documento fue generado automáticamente el 5 octubre 2019.

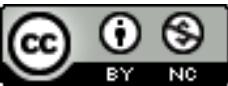

Laboreal está licenciado com uma Licença Creative Commons - Atribuição-NãoComercial 4.0 Internacional. 


\title{
¿Hasta qué punto y cómo puede conceptualizarse el trabajo informal?
}

\author{
Até que ponto e como podemos conceptualizar o trabalho informal? \\ Jusqu'où et comment peut-on conceptualiser le travail informel? \\ Limits of conceptualizing informal work?
}

Tine Manvoutouka

\section{Introducción}

1 Si bien en la actualidad se admite que la noción de desarrollo abarca dimensiones políticas, económicas, sociales y culturales, la misma está no obstante estrechamente asociada al crecimiento económico. En efecto, desde el punto de vista histórico, el desarrollo hace siempre más o menos explícitamente referencia al proceso de industrialización que Europa conoció en el siglo XIX. Efectivamente la revolución industrial modificó en profundidad el mundo laboral en Occidente y contribuyó al desarrollo económico y social de las personas. De esta forma, si el estudio del mundo laboral ha acompañado el desarrollo económico y social en Europa, ¿No debería entonces concederse la misma atención al trabajo en África negra? La cuestión del trabajo aparece, en efecto, desde el origen de las teorías del desarrollo como subordinada a la del crecimiento. Los estudios sobre el desarrollo y el trabajo en África negra revelan una categoría extranjera a los análisis económicos existentes, el trabajo informal : el trabajo que " no sirve para nada " en términos de crecimiento (Lautier, 2012). El sector informal no es desde luego una especificidad de las economías africanas. En Brasil, el trabajo informal representa un $60 \%$ de la actividad, supone un $50 \%$ de la actividad global y hasta dos tercios en África, con las especificidades históricas y contextuales de cada región del mundo. Sin embargo, las características y la importancia económica y social de este sector en África le confieren un carácter singular. En las grandes ciudades del Sahel, se trata del principal proveedor de empleo, 
que agrupa entre un $65 \%$ y un $80 \%$ del empleo urbano. Un $80 \%$ de los nuevos empleos se crea en el sector informal (Informe OIT, 2007-2008). El trabajo informal ocupa así un lugar central en los debates en materia de ciencias sociales del desarrollo. Este artículo se propone cuestionar su definición, su pertinencia y sus funciones.

\section{Definición clásica del trabajo informal}

\subsection{Emergencia de la noción de informal}

2 La literatura sobre el "sector informal » es inmensa, tanto en las publicaciones de las instituciones internacionales, como en las publicaciones académicas. La palabra “informal » tuvo éxito en los años 70 en la literatura socioeconómica de los países del tercer mundo. Este sector es efectivamente uno de los factores en los que reposa la dinámica de las economías en desarrollo y, en particular, las del continente africano, donde garantiza una gran parte del empleo y aporta una respuesta a las necesidades elementales de las poblaciones. En África negra, el sector informal agrupa actividades como los pequeños comercios ambulantes, bancos informales, mutuas informales, talleres de zapateros, sastres, alfarería, carpintería, artesanía, agricultura urbana, reparación de automóviles, transporte, y también el trabajo doméstico, que es el menos visible pero el más extendido (Verlet, 2005).

3 Fue el célebre informe Kenya de la Organización Internacional del Trabajo (OIT) el que empleó por primera vez la expresión de sector “informal» en 1972, para designar realidades muy diversas. El informe Kenya enumera 7 características para agrupar las actividades que escapan así de las normas legales y estadísticas :

- facilidad de acceso a la actividad

- utilización de recursos locales

- propiedad familiar de la empresa

- escala de actividad reducida

- uso de técnicas que privilegian el recurso a la mano de obra

- cualificaciones adquiridas al margen del sistema oficial de formación

- mercados competitivos y sin regulación.

4 Esta definición no es en modo alguno definitiva y no goza de unanimidad entre los expertos en el propio seno de estas instituciones internacionales. De esta forma, cada autor suele elaborar su propia definición en función de su terreno de estudio. Este problema de definición da cuenta a la perfección del polimorfismo del sector informal y de la dificultad de englobar las diversas realidades observadas. Así, puede pensarse que la generalización del uso de la palabra "informal» se debe principalmente a su imprecisión. Lo “informal» cuestiona efectivamente la definición del trabajo en sentido estricto, es decir, el trabajo moderno, formal y asalariado. Ahora bien, el salariado es solo un marco social posible entre otras formas de encuadramiento del trabajo (Vatin, 2010). Desde un punto de vista epistemológico, nos enfrentamos por lo tanto a una noción vaga.

5 Sin embargo, cabe destacar dos criterios que generan la unanimidad de los investigadores para definir el sector informal, el de la dimensión -por ejemplo, todas las estructuras de menos de 5 personas- y el de la inobservancia de la ley ya que no todas las estructuras se registran en la contabilidad nacional. Otra cuestión que viene rápidamente a la mente cuando tratamos de definir el sector informal es 
evidentemente la de la frontera entre actividades ilícitas y actividades lícitas no reguladas. También en este caso, algunos informes excluyen las actividades delictivas de sus campos de estudios; en otros casos, la delimitación resulta menos obvia. En resumen, el campo de la economía informal se circunscribiría a las actividades ilícitas conforme a su naturaleza pero ilegales en su funcionamiento (Lautier, 1994). Se habla entonces de actividades "alegales» o "apolíticas", en lugar de actividades ilegales (Ngary, 2008).

6 En 1993, la OIT adopta una definición internacional del sector informal con objeto de poner fin a esas confusiones entre ilegal, subterráneo e informal, y lo define " como un conjunto de unidades que producen bienes y servicios con objeto, principalmente, de crear empleos e ingresos para la personas implicadas. Estas unidades, que poseen un débil nivel de organización, operan a pequeña escala y de manera específica, con poca o ninguna división entre el trabajo y el capital como factores de producción. Las relaciones laborales, en caso de que existan, se basan sobre todo en el empleo ocasional, las relaciones de parentesco o las relaciones personales y sociales más que acuerdos contractuales que comporten garantías en regla» (Charmes, 2002). Esta nueva definición estadística -con finalidad claramente operativa- ha permitido comprender los mercados de trabajo contemporáneos de los países en desarrollo y aportar una cartografía estadística.

\subsection{Enmarcar el trabajo informal}

7 La problemática que dinamiza estas investigaciones sobre el sector informal es ante todo de orden práctico y político : se trata efectivamente de saber si el sector informal ofrece una solución a la pobreza y al "subdesarrollo». De esta forma, pueden distinguirse dos épocas en la visión del sector informal promovida por las instituciones internacionales. Una época de políticas de "formalización " del sector informal, es decir, en la que se ha querido regular estas actividades, enmarcarlas, promoverlas, aportando medios suplementarios para el desarrollo de las actividades de los trabajadores del sector informal. Y una época en la que el sector informal se convierte en el lugar de absorción de los efectos sociales de la crisis, es decir, en la que el sector informal pudo reabsorber las pérdidas de empleos del sector público y la industria derivadas de las políticas de rigor de los planes de ajuste estructural. Efectivamente, la multiplicidad de las actividades y su función en términos de empleo y contribución al PBI requieren que las políticas públicas tengan en cuenta el sector informal. ¿Necesitan estas actividades, para ser duraderas, el apoyo del Estado ? ¿Cómo garantizar un trabajo decente -según la OIT- a los trabajadores de este sector sin regulación estatal ? Por ello, la problemática planteada por los poderes públicos es la siguiente : ¿Cómo facilitar la integración del sector informal en la economía y las instituciones nacionales para aumentar su rendimiento y mejorar la protección social de los trabajadores sin por ello reducir su capacidad de absorción de mano de obra y de generación de ingresos?

No obstante, las buenas razones para enmarcar el sector informal forman parte de estas evidencias que deben debatirse. Porque enmarcar una actividad quiere decir imponer una lógica desde arriba. Ahora bien, los orígenes de estas actividades, su naturaleza práctica y la cultura que les confiere sentido, constituyen tres dificultades principales para una formalización de las mismas. Efectivamente, el éxito de las políticas de “formalización” del sector informal es muy mitigado: ¿A quiénes se dirigen estas 
políticas de ayuda? ¿Son realmente las que reciben ayuda las que más lo necesitan? ¿Se apoya a todas las pequeñas empresas o a las que entran más fácilmente en los marcos ya existentes? ¿Cuál es la lógica que guía a los protagonistas de estas actividades, una lógica de acumulación o una lógica de reproducción familiar? ¿Cuáles son sus necesidades reales?

9 Finalmente, diremos que el sector informal no está constituido contra el derecho existente sino al margen del derecho y, que el sector informal no es un "sector ", es decir, un ámbito definido de actividad. En efecto, aunque encontremos en la literatura de las ciencias sociales el desarrollo de las nociones de "economía ", "sector " y “trabajo" para hablar de lo informal, estas categorías plantean un problema metodológico central. Hablar de una "economía " informal supone de entrada una autonomía respecto a la vida social en general. Hablar de "sector » reduce lo informal a sus funciones económicas (" no sirve para nada») o sociales (creación de empleo y lucha contra la pobreza). En nuestro análisis, utilizaremos sobre todo el término “ trabajo » informal que permite una visión más microscópica y que permite superar el dualismo sectorial formal/informal. El trabajo informal no puede confinarse en un sector debido a su extrema heterogeneidad y por su presencia en todos los niveles de la vida económica y social de los países del sur. Resulta difícil efectivamente separar las actividades formales de las actividades informales, un empleo formal de un empleo informal. De esta forma, ¿No refleja la noción de informal una debilidad terminológica, una ausencia de análisis real de una forma de trabajo inaprehensible a través de instrumentos históricamente inadaptados ? Porque la definición de "lo informal » no se agota en lo contrario a lo formal, que supondría negar sus orígenes, su naturaleza y su cultura. Por ello, defendemos la siguiente tesis : para comprender y transformar una actividad, es necesario entender su sentido, la lógica que la guía.

\section{Definición de trabajo informal pasando por un análisis de la actividad}

\subsection{El trabajo informal, una forma de organización social}

10 Aunque resulta evidente que las actividades que componen el trabajo informal no son “informales » en sentido estricto, es decir, sin forma, ¿qué es lo que diferencia sin embargo del trabajo formal?

11 El trabajo informal es efectivamente un trabajo en sí mismo, con normas y valores. Resulta más difícil delimitar porque la realidad de la vida del colectivo es tal que lo económico se mezcla con las actividades sociales (Nouroudine, 2010). ¿Cómo delimitar por ejemplo en una misma actividad tres funciones diferentes, en particular, de venta, donación y auto subsistencia? De esta forma, limitar lo informal al sector económico sería demasiado reductor. Por una parte, lo informal constituye ante todo una forma de organización social que engarza lo económico en lo social. Por otra parte, el sector informal mantiene relaciones estrechas con el sector económico regulado, tanto en sus actividades similares como en sus razones de existencia -o de resistencia- debidas a las dificultades de la economía oficial para satisfacer las necesidades de la población. El trabajo informal se encuentra en todas a las actividades -rurales, de servicios, comerciales, urbanas, del sector público. La subcontratación informal necesita grandes empresas internacionales, los talleres de reparación y mantenimiento se abastecen en 
el mercado formal. Se observa tal interdependencia entre el trabajo formal e informal que no sabría entenderse un empleo formal independientemente de un empleo informal. Efectivamente, ambas actividades -formal e informal- se combinan a menudo para poder satisfacer las necesidades (por ejemplo, una actividad asalariada en un ministerio público combinada con una actividad de platos cocinados en forma de puesto en casa o la utilización de material de oficina para fines personales).

El trabajo informal responde a una lógica diferente de la economía oficial, en la medida en que no sirve al crecimiento económico. ¿Pero no cumple otras funciones? Aunque la finalidad de la producción informal no es la acumulación del capital y los recursos no se reinvierten necesariamente en la producción, estos representan en cambio una inversión relacional (Latouche, 1998). El dinero ganado vuelve a ponerse enseguida en circulación en redes como en las "tontinas " [1]. El trabajo informal genera ingresos aunque sean bajos, facilita empleos aunque sean precarios; dos criterios considerados de hecho en la definición internacional de la OIT. Además de sus funciones económicas, este contribuye a una regulación a la vez política y local.

\subsection{Aportación de la metodología ergológica al análisis del trabajo informal}

¿Cómo saber lo que tiene sentido o significación en el trabajo? ¿Cómo pensar las relaciones laborales en África? ¿Qué modo de producción de conocimiento utilizar?

Según el sociólogo camerunés Jean-Marc Ela, deben adoptarse precauciones metodológicas y epistemológicas cuando se habla de economía informal. Por ejemplo, ¿Qué significa emprender en este sector? En opinión de Jean-Marc Ela, los "aficionados" $\left.{ }^{2}\right]$ no son " empresarios». No responden a las mismas normas. En la economía informal, a menudo denominada igualmente economía popular, la contratación no responde al criterio de competencia, sino que se basa en un sistema que califica como discriminación. El jefe suele ser un miembro de la familia, el clan o la aldea. Así, las normas de eficacia y productividad que rigen el mundo de las empresas del sector privado no se encuentran en la economía popular. Esta responde sobre todo a una necesidad de seguridad. Además, las actividades de este sector no presentan un riesgo elevado: el capital invertido es muy débil, existe un rendimiento rápido del capital invertido (a menudo un solo día), suele tratarse de la reventa al por menor en la que prima la relación de proximidad. Ela habla de normas de proximidad y del instante (Ela, 2009), producto de una relación de confianza. Así, en términos de asunción de riesgo y acumulación de capital, los agentes de la economía popular serían emprendedores pero no empresarios (Ela, 2009). Otro ejemplo se refiere al aprendizaje, donde la relación entre jefe y aprendiz se sitúa al margen de las normas legales establecidas y se inscribe en el sistema de obligaciones de parentescos reconocidas en las sociedades africanas. Así, las normas dominantes en el aprendizaje no son salariales, sino cotidianas, jerárquicas y afectivas. Pagado al comienzo de la formación por un pariente, el aprendizaje no se remunera y, generalmente, tiene una duración de 3 años. Aunque responda a normas organizativas muy estrictas, estas no están codificadas por escrito. El aprendizaje se disfraza de tutela, con una monopolización de la autoridad y una estructura jerárquica fuerte, en particular, en la dirección y la vigilancia de los aprendices. 

privatizaciones no son suficientes para aprehender las relaciones laborales en África. Para comprender las relaciones laborales y empresariales en África, es necesario decodificar los sistemas de valores que trabajan en profundidad los protagonistas del trabajo. Efectivamente, ¿Cómo transformar el trabajo de las personas cuya visión del mundo se ignora, así como el sistema normas que determinan el comportamiento de los agentes en una sociedad dada? ¿De qué África estamos hablando ? ¿Cuál es lo cotidiano de la juventud en África en la actualidad ? Solo a través de la realización de encuestas in situ pueden descubrirse las relaciones entre el individuo y la familia, entre el individuo y la sociedad, con objeto de superar los enfoques que consideran las prácticas sociales como un obstáculo para el desarrollo. Por ejemplo, la ideología del comunitarismo africano enmascara las tensiones y antagonismos que pueden existir entre hombres y mujeres, entre mayores y jóvenes, entre pobres y ricos (Ela, 2009) en las sociedades contemporáneas. Un análisis de la actividad laboral informal permite, por el contrario, discernir las estrategias de adaptación y “ firmas específicas de regulación del trabajo ” (Ela, 2009).

16 La metodología ergológica propone efectivamente producir conocimientos y transformar el trabajo partiendo de las reservas alternativas presentes en las situaciones laborales. Propone hacer visibles los saberes de las personas que tratan de transformar su medio de vida y de trabajo. No obstante, nos hallamos frente a dos obstáculos cuando tratamos de aprehender el trabajo informal.

En primer lugar, las normas antecedentes que enmarcan el trabajo -el trabajo prescrito vehiculado generalmente a través de lo oral son difícilmente formalizables y presentan un riesgo de error de interpretación en caso de formalización de las mismas por un tercero. Asimismo, la existencia de una pluralidad de sistemas de normas en el trabajo informal hace que estas normas resulten difícilmente identificables y separables. Efectivamente, puede apreciarse que el trabajo informal no entra inmediatamente en una forma de institucionalización del trabajo conocida como el trabajo industrial o el trabajo tradicional o incluso una forma híbrida. Se adivinan igualmente las dificultades para verbalizar, los saberes para formalizar invertidos en su actividad por parte de los protagonistas del trabajo.

18 El segundo obstáculo se refiere a la propia categorización de los objetos en ciencias sociales. Los objetos de las ciencias sociales son objetivos móviles : estos sujetos-objetos tienen debates de normas. En efecto, si toda actividad laboral es un lugar de arbitraje entre normas económicas, organizativas, sociales, personales, etc., entonces es conveniente considerar las consecuencias epistemológicas que implica tal definición ergológica del trabajo. El trabajo se convierte así en un objeto de estudio en constante evolución, es decir, las actividades humanas tienen una reactividad propia y modulan a su manera los marcos conceptuales disciplinarios, las normas y métodos. La metodología ergológica arraiga efectivamente esta separación perpetua entre los conceptos y los objetos que tratan de describir en una antropología filosófica que concibe al ser humano como un ser de actividad. La actividad cuestiona todos los conceptos que tratan de describirla (Schwartz, 2000). Los conceptos forjados en las disciplinas deben regresar a lo real y unirse a los movimientos renunciando a poder explicarlo totalmente (Yvon \& Durand, 2011). 


\section{Conclusión}

En conclusión, diremos que el trabajo informal no debe limitarse ni a un sector ni a una forma de ilegalidad sino que debe definirse en función de su naturaleza práctica, sus orígenes y su propia cultura. En efecto, la voluntad de formalizar lo informal supone cuestionar su eficacia, dudar de su racionalidad. El análisis del trabajo en todas sus formas y su propia historicidad permitirá eventualmente salir de la vaguedad terminológica para hablar del trabajo en África negra. Porque ante todo, se trata efectivamente de un problema de terminología. ¿Cómo hablar de realidades laborales que no entran en los marcos conocidos? ¿Cuál es la pertinencia de las nociones de " salariado », " capital », " división del trabajo », incluso de " trabajo » para el análisis de las actividades productivas en África ? Por último, habida cuenta de que la noción de trabajo mezcla tanto una intención de conocimiento como una intención de acción, resulta aún más urgente ceder un lugar al análisis del trabajo en las ciencias sociales y del desarrollo con objeto de poder evaluar regulaciones locales eficaces.

\section{BIBLIOGRAFÍA}

Charmes, J. (2002). Les origines du concept de secteur informel et la récente définition de l'emploi informel. Worldbank working paper.

Ela, J.-M. (2009). Travail et entreprise en Afrique, fondements sociaux de la réussite économique.

Karthala : Paris.

Latouche, S. (1998). L'autre Afrique, Entre don et marché. Albin Michel : Paris.

Lautier, B. (1994). L'économie informelle dans le tiers monde. La Découverte : Paris.

Lautier, B. (2012). Article développement in Jobert, A., Mias, A., Lallement, M., \& Bevort, A., (dir.) Dictionnaire du travail. p. 178-184. PUF.

Ngary B. N. (2008). La modernisation quotidienne au Gabon. La création de toutes petites entreprises. Paris : L'Harmattan.

Nouroudine, A. (2010). Comment connaître le travail quand le travail n'est plus le travail ?. Ergologia, 3, 105-126.

Rapport (2007-2008). Economie informelle Afrique de l'Ouest. Bureau International du Travail. Schwartz, Y. (2000). Le paradigme ergologique ou un métier de philosophe. Toulouse : Octarès. Vatin, F. (2010). Entretien avec François Vatin. Le Philosophoire, 34, 33-45.

Verlet, M. (2005). Grandir à Nima (Ghana) Les figures du travail dans un faubourg populaire d'Accra. Paris : Karthala.

Yvon F., \& Durand, M. (dir.) (2011). Réconcilier recherche et formation par l'analyse de l'activité. Bruxelles : De Boeck. 


\section{NOTAS}

1. Una «tontina», proveniente del francés «tontine», es una asociación cuyos miembros comparten sus cuotas y reciben por turnos el ahorro reunido.

2. Se trata de una adaptación del término «bricoleurs " en francés para denominar a aquellos que realizan diversos oficios informales. El término original se refiere a aquellos que realizan bricolaje el fin de semana (pintar una ventana, componer el auto, etc.).

\section{RESÚMENES}

El objeto de este artículo consiste en interrogarse acerca del concepto de trabajo informal con la finalidad de saber hasta qué punto y cómo puede conceptualizarse el mismo. Efectivamente, la definición dada por la OIT del concepto de trabajo informal posee una finalidad explícitamente operativa. No obstante, la realidad del mundo laboral en África supera ampliamente dicha definición estadística: ¿Cómo dar cuenta entonces de esta forma de trabajo que no parece responder a las normas de referencia que enmarcan el trabajo en sentido estricto en una sociedad mercantil y de derecho ? ¿En qué medida una definición basada en la actividad permite aprehender el trabajo informal? Desde este punto de vista, ¿cómo concebir los vínculos entre desarrollo y las racionalidades específicas del trabajo informal?

O objectivo deste artigo irá consistir em questionar o conceito de trabalho informal para saber até que ponto e como é que pode ser conceptualizado. Com efeito, a definição do BIT para o conceito de trabalho informal tem, explicitamente, uma finalidade operacional. No entanto, a realidade do mundo do trabalho em África ultrapassa amplamente esta definição estatística : como definir então esta forma de trabalho que parece não corresponder às normas de referência que enquadram o trabalho stricto sensu numa sociedade mercantil e de direito ? Até que ponto uma definição pela actividade permite abordar o trabalho informal ? Nesta perspectiva, como conceber as ligações entre o desenvolvimento e as racionalidades específicas do trabalho informal?

L'objet de cet article consistera à interroger le concept de travail informel afin de savoir jusqu'où et comment celui-ci est conceptualisable. En effet, la définition par le BIT du concept de travail informel est explicitement à finalité opérationnelle. Cependant, la réalité du monde du travail en Afrique déborde largement une telle définition statistique: alors comment rendre compte de cette forme de travail qui ne semble pas répondre aux normes de référence qui encadrent le travail stricto sensu dans une société marchande et de droit? Jusqu'où une définition par l'activité permet-elle d'appréhender le travail informel? Dans cette perspective, comment concevoir les liens entre le développement et les rationalités spécifiques du travail informel?

This article will question the notion of informal work in order to know how far it can be considered as a concept. Indeed, the International Labour Organization's definition of the informal work concept has clearly an operational purpose. However, the reality of the working world in Sub-Saharan Africa widely extends beyond such a statistical definition. How can we talk then about a form of work that does not seem to respond strictly to the reference work norms in a strict sense in a market and legal oriented society? How far can a bottom-up definition, starting from micro-activity, apprehends informal work? In this perspective, how can we 
conceive the relationship between the development and the specific rationalities of informal work?

\section{ÍNDICE}

Palabras claves: trabajo informal, concepto, desarrollo, Africa Subsahariana Mots-clés: travail informel, concept, développement, Afrique Subsaharienne Keywords: informal work, concept, development, Sub-Saharan Africa

Palavras-chave: trabalho informal, conceito, desenvolvimento, África Subsaariana

\section{AUTOR}

\section{TINE MANVOUTOUKA}

Doctorando en el Centro de Epistemología y Ergología Comparativas, Université d'Aix Marseille, CNRS, CEPERC UMR 7304, 13621 Aix-en-Provence cedex, France.

roth.tine@gmail.com 